\title{
A Review - Parametric Optimization of Process Parameter for Electro Discharge Machining of Inconel alloy
}

\author{
Prof. Kaushik J. Prajapati' ${ }^{1}$, Prof. B.V Bhuva², Prof. Dr. V.D Patel ${ }^{3}$, Prof. Mehul B. Patel ${ }^{4}$ \\ 1,4 Assistant Professor, B S Patel Polytechnic, Ganpat University, Gujarat, India \\ ${ }^{2,3}$ Assistant Professor, U V Patel College of Engineering, Ganpat University, Gujarat, India
}

\begin{abstract}
New materials are coming day by day in to apply to continuous call for plane upkeep, clinical subject and defense for machining complicated shapes. due to improved hardness and high electricity of recent materials, the traditional machining method cannot meet the requirement, so optimization is one of the strategies used in production quarter to arrive for the pleasant production conditions, that's critical want for industries closer to production of excellent products at lower fee.

This paper studied the choicest set of method parameters (i.e. material removal charge (MRR), device wear price (TWR), floor roughness) of electric discharge machining for different alloys. The important EDM machining parameters affecting the performance measures of the discharge current, pulse on time, pulse off time, arc hole and obligation cycle.
\end{abstract}

Key Words: Process Parameter, EDM, Microstructure, Optimization.

\section{INTRODUCTION}

The essential EDM parameters affecting the performance measures of the method are pulse on time, discharge present day, pulse off time, duty cycle and arc gap. it's far an important challenge to select the proper combination of machining parameters for optimization of EDM. Essentially, the machining parameters are selected on the premise of operator's experience or data supplied by way of EDM producer. records furnished by way of the producers concerning the parameter setting is beneficial simplest for most typically used steels, such facts is not to be had for unique materials like ceramics and composite substances. for this reason it's miles vital to recognize the have an impact on of different factors at the EDM technique. Analytical and statistical methods are used to choose the best combination of procedure parameters for an finest machining overall performance. numerous author use a exceptional aggregate of process parameters.

\subsection{Electric Discharge Machining}

Electric discharge machining is a thermo electric system in which heat electricity of spark is used to do away with material from the workpiece. A spark is produced among electrodes and its location is decided by the narrowest hole among the two electrodes. The frequency of sparking may be as excessive as lots of sparks in keeping with $2 \mathrm{~d}$. Temperature of very small region beneath the spark is very high which results in partial melting and partial vaporization of material from the localized vicinity from both device and workpiece. The fabric is gets rid of inside the form of craters. Ultimately, the cavity ids produced in the workpiece is approximately the replica of the tool. To reduce the damage of the device the operating parameters and polarity ought to be decided on carefully.

\subsection{Optimization}

Now a days, complex manufacturing processes, it's miles often to decrease the several reaction concurrently instead of optimization one response at a time. In multi reaction problems the objective is to decide the most appropriate settings of factors on the way to concurrently optimize the several responses. Consequently the goal could be to pickout the most efficient placing of the variables which have an effect on all the responses on the equal time. Those styles of issues may be without difficulty solved with the assist of optimization techniques like taguchi method. Most of the crucial business problems analyzed through Taguci method and deliver the high best and really great consequences to the consumers. This analysis may be used to take a look at on which parameters that are to be most accurately measured, as a result determining the maximum influencing enter parameters on the version reaction. Consequently, sensitive analysis plays an vital function in figuring out on what parameters which might be to be most as it should be measured, hence decide the most influencing input parameters at the model response. The sensitivity equations are calculated by means of differentiating the advanced empirical relation with admire to the factors

\section{LITERATURE REVIEW}

An adaptive manage machine for system monitoring, identity, and manipulate within the twine electric discharge machining method were evolved by using Yan. it's been realized that the cord breaking has been managed by means of adjustment of pulse interval of each pulse cycle of supply. An adaptive neuro-fuzzy inference machine version for the prediction of the surface roughness of machined floor the usage of wire EDM procedure as a feature of manner parameters inclusive of open circuit voltage, pulse duration, and twine feed price. From the experimental consequences, it 


\section{International Journal of Scientific Research in Engineering and Management (IJSREM)}

has been located that the proposed manipulate machine has progressed the surface first-rate inside the EDM process [1]. added a used pleasant smart system based at the knowledge of the skilled operators for the choice of the EDM system parameters for machining AISI 4340 chrome steel. The gadget has been provided with a compact choice device based on professional regulations and enabled an unskilled person to select vital parameters which result in lower electrode put on price and higher surface satisfactory [2-3]. An adaptive manage device which without delay and automatically has regulated the device downtime for improving the system overall performance within the EDM method. it's been observed that this adaptive device would enhance the machining charge, due to the automatic adjustment of the spark hole [4]. a new pulse discriminating and manage machine for method tracking in the EDM process. The consequences of pulse c programming language, machining feed charge and workpiece on the variant of the proportion of regular spark, arc and brief circuit in the overall spark have been mentioned. The experimental outcomes have indicated that the advanced manage gadget has appreciably decreased the arc discharge within the EDM method to gain solid machining [5]. Mathematical modeling of white layer depth to correlate the dominant enter parameters of the WEDM manner, comprising of a rough reduce followed via a trim reduce within the system, typically die steel (M2-hardened and annealed) turned into machined the usage of brass twine as an electrode. An experimental plan of rotatable critical composite design in RSM such as enter variable pulse on time all through the difficult cutting and pulse on time offset and cutting velocity at some stage in trim reducing has been hired to perform the experimental have a look at and concluded that the white layer depth increases with increasing pulse on time in the course of the primary cut and reduces with increasing pulse on time for the duration of trim reducing. With increasing reducing velocity in trim slicing, the white layer intensity-first reduces and then starts growing [6]. the connection of manner parameters in EDM of CK-45 steel with novel tool electrode fabric including $\mathrm{Al}-\mathrm{Cu}-\mathrm{Si}$-TiC composite product the usage of a powder metallurgy technique. in this take a look at, height modern-day, dielectric flushing stress, and pulse on time are considered as input technique parameters and the manner performances which includes MRR and TWR were evaluated. The evaluation turned into completed with the assist of response surface method. It turned into concluded that the height cutting-edge changed into located to be the most important issue effecting both the MRR and TWR while dielectric flushing strain has little effect on both responses. Al-Cu-Si-Tic electrodes had been located to be extra sensitive to top current and pulse on time than conventional electrodes [7]. the relationship of process parameters in EDM of Tungsten carbide changed into used as the workpiece cloth and graphite as an electrode. in this have a look at peak modern, voltage, pulse on time and pulse off time are considered as input procedure parameters and the method performances such as metallic removal charge, electrode put on price, and surface roughness. The Taguchi method has been used to formulate the experimental layout, to analyze the impact of each parameter on the machining characteristics, and to expect the best EDM parameters. It was concluded that the peak present day of EDM in particular affects the electrode wear and floor roughness and the heart beat on time in large part impacts the metal removal charge [8].

The impact of system parameters like Pulse on time, Pulse off time, deliver Voltage, top current on material eliminated fee and electrode wear. The Tungsten Carbide changed into used as the workpiece material and Copper Tungsten as an electrode. the full factorial layout of experiment became used to analysis the best situation of machining parameters. the author concluded that for floor roughness the maximum influential thing changed into voltage accompanied by means of pulse off time, peak cutting-edge and in case of fabric elimination price, it was seen that the heartbeat on time thing changed into the maximum influential, observed by way of voltage, top present day and pulse off time [9].

Empirical relations concerning machining parameters and the responses in studying the machinability of the stainless steel AISI 304 the use of copper electrode. The machining elements used have been voltage, the rotational pace of electrode and feed fee over the responses MRR, EWR, and SR. The response floor method become used to research the relationships and parametric interactions among the three control variables on the MRR, EWR, and SR. the advanced models show that the voltage and rotary movement of electrode are the maximum significant machining parameters influencing MRR, EWR, and SR [10] The impact of system parameters like Pulse on time, Discharge current and Diameter of the electrode on fabric elimination price, device wear fee and over reduce. The experiment used AISI P20 tool metallic as the workpiece and U-fashioned copper device as an electrode with the inner flushing gadget. The $\mathrm{S} / \mathrm{N}$ ratios used for minimizing the TWR and maximizing the MRR and Taguchi technique used for optimization the method parameters. It changed into concluded that pulses on time become the most influencing element for MRR and then discharge cutting-edge and the final one is the diameter of the device. MRR increased with the release current and in case of the device put on charge, the most influencing aspect is a pulse on time then discharge present day and after that diameter of the tool [11].

They advanced quadratic fashions for the machining fee, floor roughness and dimensional deviation to correlate the dominant machining parameters: pulse on time, pulse off time, peak present day, spark gap voltage, cord feed \& tension in cord EDM procedure for natural titanium. An experimental plan of the container-Behnken based totally on RSM has been carried out to perform the experimentation work and decided that the maximum sizeable parameters with respect to the response variables are located to be pulse on time, pulse off time, height current \& spark gap voltage and additionally conclude that the machining price, floor roughness, and dimensional deviations have been pretty well fitted with the experimental consequences with ninety five $\%$ confidence degree [12].

The impact of manner parameters and their interactions viz., voltage, pulse on time, present day and pulse off time on the material removal fee in chrome steel (304) a workpiece. 


\section{International Journal of Scientific Research in Engineering and Management (IJSREM)}

Signal to noise ratio $(\mathrm{S} / \mathrm{N})$ and evaluation of variance (ANOVA) turned into used to research the impact of the parameters on MRR and Taguchi approach used to locate the optimum slicing parameters. It became concluded that the two primary giant elements that affect the MRR are pulse current and pulse on time [13].

A non-linear mathematical model to represent the technical behavior of WEDM. Experiments were conducted with 8 procedure parameters viz. discharge contemporary, pulse on time, pulse off time spark voltage, cord tension, cord feed, servo feed and flushing pressure of the dielectric fluid to narrate them with procedure responses viz. cloth removal charge and floor roughness. The experiment become done with $\mathrm{H} 13$ warm Die tool steel as the workpiece and stratified cord (Zinc covered copper cord) as an electrode. the gray based totally Taguchi technique has been applied to evaluate top-quality parameter mixture to gain maximum MRR, minimum roughness value; with the chosen experimental area. It changed into concluded that the grey-Taguchi technique, is maximum perfect and suitable for the parametric optimization of the wire-reduce EDM technique whilst the use of the multiple performance characteristics along with MRR and SR for machining the H13 or for the matter for any other material [14].

The optimization of the method parameters in the course of machining of Inconel-600 and molybdenum cord as an electrode in WEDM via the use of response floor method. Four enter procedure parameters viz. peak present day, pulse on time, pulse off time and twine feed charge were taken into consideration to take a look at the method overall performance in terms of MRR. in this take a look at, the parametric optimization method using Taguchi's robust design turned into proposed for WEDM. The evaluation of variance becomes accomplished to observe the impact of procedure parameters on method performance. It became found that pulse on time, pulse off time, top modern become the most effective parameters for MRR [15].

The impact of manner parameters which include discharge modern-day, pulse-on-time and obligation cycle for technique overall performance standards such as metallic elimination fee and electrode put on charge. Experiments are carried out on tungsten carbide with the copper electrode in a die sinking EDM. response surface technique have been employed to increase a mathematical version and to set up empirical relationships among system parameters and procedure responses. It become located that the height present day became observed to be the most vital factor effecting both the MRR and EWR. It have been observed that the most MRR changed into finished at 10 A discharges cutting-edge, $50 \mu$ s pulse on time and eight duty cycle and minimal EWR had been carried out at 6 A discharge modern, $10 \mu$ s pulse on time and eight duty cycle [16].

The reaction of technique parameters which include top cutting-edge, pulse on time, pulse off time and device carry time for technique performance standards together with metal removal price, device put on price, and surface roughness. Experiments are carried out on titanium highquality alloy with electrolytic copper die sinking EDM with servo head, steady hole voltage, and fine polarity. It turned into found that MRR increases with growth in top modernday, TWR decreases with boom in current up to nine Ampere then increases constantly, SR step by step increases up to 12 A after that rate of decrease or growth is nearly zero. MRR and TWR boom with an growth in pulse on time up to $20 \mu \mathrm{sec}$ to peak fee then decreases constantly, SR decreases constantly as much as $500 \mu \mathrm{sec}$ then will increase continuously. MRR and TWR increase continuously with the boom in pulse off time as much as $50 \mu$ sec then decreases constantly, SR increases little better for low pulse off time [17].

The reaction of technique parameters including discharge present day, pulse on time, pulse off time and duty element for procedure overall performance criteria along with steel elimination rate, tool wear price, and floor roughness. Experiments are performed on Inconel-718 with copper, brass and graphite as electrode substances with CNC die sinking EDM gadget with servo head (regular hole). It was observed that evaluation of variance is performed on performance measures consisting of material elimination charge, device wear rate and floor roughness with a view to analyze the impact of essential method parameters. it is located that the fabric removal charge decreases with boom in pulse-on-time and the decrease is fast when the heartbeaton time is about beyond 2 hundred $\mu$ s. for the reason that quantity of molten metallic remains unaffected, a similarly boom in pulse-on-time consequences in a decrease of MRR. MRR will increase monotonically with an boom of obligation component. Increase in responsibility thing causes an increase in the spark power throughout the gap among the electrodes resulting in an growth of temperature which ultimately ends in boom in MRR. cloth elimination is better whilst machining with graphite electrode accompanied with the aid of copper and brass respectively. As a long way as device wear is worried, graphite tool plays superior to copper and brass device [18].

Chinmaya P Mohanty, Siba Shankar Mahapatra, Manas Ranjan Singh (2014) [19] investigated that Tool material and discharge current and pulse-on-time are the important parameters in the machinability of Inconel 718 super alloy for both the responses by taking open circuit voltage, discharge current, pulse-on-time, duty factor, flushing pressure and tool material as an input parameters and material removal rate (MRR) and surface quality.

Santosh Kumar Sahua, Thrinadh Jadamb, Saurav Dattab, Debabrata Dhupalc, Goutam Nandia had founded that [20] at low energy input, use of $\mathrm{SiC}$ powder with concentration $4 \mathrm{~g} / \mathrm{l}$ has appeared beneficial for achieving improved (maximum) $\mathrm{MRR}$, and reduced roughness average ( $\mathrm{R}$ a ), Surface Crack Density (SCD) as well as WLT \&amp; Amongst the parameters investigated (peak current, pulse-on time and powder concentration); peak current has appeared as the most significant parameter followed by powder concentration.

Rahul, Saurav Datta, Bibhuti Bhusan Biswal (2019) [21] evaluated that Increase in peak discharge current, pulse duration and duty factor individually (one varying at a time 
keeping remaining two constant) caused increased volumetric material removal rate, roughness average, surface crack density and white layer thickness.

J. Jeykrishnan, B. Vijaya Ramnath, N. Chenbhaga Ram, K. Nikhil R. Naveen Babu, D. Naveen [2018] [22] had taken current, pulse on time and pulse off time as an input parameter and proved that the current plays an important role in affecting the MRR, followed by pulse on time and pulse off time on Inconel 625 material.

Rahul, Ankur Srivastava , Dileep Kumar Mishrac, Suman Chatterjee, Saurav Dattae, Bibhuti Bhusan Biswal, Siba Sankar Mahapatrag (2017) [23] experimented that Peak current appeared as the most significant parameter, whilst flushing pressure has been found the least significant one by taking gap voltage, peak discharge current, pulse-on time, duty factor and flushing pressure as a input parameters and Material Removal Rate (MRR), Electrode Wear Rate (EWR), Surface Roughness(RD, Surface Crack Density (SCD), White Layer Thickness (WLT), and Micro Hardness (MH) as a output parameters.

Bighnesh Kumar Sahua, Saurav Dattab, Siba Sankar Mahapatra (2018) [24] has taken Peak discharge current, pulse-on duration and gap voltage and proved that MRR, SCD, and WLT are directly proportional to the pulse-on time. Increase of pulse-on time in turn results increased energy input during the machining process which increases MRR, SCD as well as WLT.

Rahul, Saurav Datta, Bibhuti Bhusan Biswal, Siba Sankar Mahapatra (2018) [25] proved that the optimal process parameters setting appears as (A4B2C1D5E5) i. e. $0 \mathrm{CV}=80 \mathrm{~V}$, $\mathrm{IP}=5 \mathrm{~A}$, Ton $=100 \mu \mathrm{s}, \tau=85 \%$ and $\mathrm{FP}=0.6$ bar open circuit voltage $(\mathrm{OCV})$ is the most significant parameter to influence machining performances.

Shishir Raja, Rahul b, Himanshu Ranjan Sinhac, Shivanid, Shuvam Dase, Shreetanu Guhaf, Aazimg, Dipraj Banikh, B.C Routarai (2020) [26] researchers found that the optimum process parameters found out as (A1B4C1D3) i.e. IP=4A, $\mathrm{Vg}=30 \mathrm{~V}$, Ton $=50 \mu$ s and $\tau=85 \%$. gap voltage $(\mathrm{Vg})$ has the highest significance on influencing the machining performances by taking Peak Current (IP), Open Voltage (Vg), Pulse-On-Time (Ton) \&amp; Duty Factor $(\tau)$.

A. Thakura, S. Dewangana, Y. Patnailca, S. Gangopadhyaya (2014) [27] summarizes that Microhardness increased with increase in cutting speed, Coated tool resulted in reduction in microhardness in the surface and sub-surface region, The total average error of microhardness is 1.07 and 1.18 with uncoated and coated tools found respectively when input parameters are cutting speed and multilayer (TiN/TiCN/A1203/ZrCN) coating.

Neelesh Singh, B.C. Routara, Diptikanta Das (2018) [28] evaluated that the current increases then MRR increases. Surface finish varies directly with current by taking gap voltage (Vg), peak current (Ip) and pulse on time (Ton) as an input Parameters.

A. Thakura, A. Mohantya, S. Gangopadhyaya, K.P. Maitya (2014) [29] proved that the chip thickness ratio decreased with progression of machining duration, the chip curl radius increased with progression of machining duration and increase in cutting speed when machined with uncoated inserts, The deformation of the chip was more at low speed resulting in a low chip thickness ratio than that at high cutting speed. The average flank wear increased with both cutting speed as well as with machining duration and the chip curl radius increased with progression of machining duration and increase in cutting speed when machined with uncoated inserts by taking cutting speed as input parameter.

\section{EXPERIMENTAL METHODS}

The variety of experiments was analyzed to look at the effect of diverse machining parameters on EDM manner. those studies have been analyzed for exceptional alloy to research the results of modern-day, pulse on time and pulse off time on metal elimination charge, device wear charge, relative put on ratio and surface roughness.

In this test, magnetic area is added between the machining gaps the use of everlasting magnet N35 with external magnetic field of zero.3T as proven in determine 1. For MEDM magnetic subject line advanced parallel to the work piece floor such that it's far perpendicular to electric discipline strains. The pass made from the present day with the magnetic subject gives Lorentz pressure as visible in equation 1 that's maximized when the modern vector and the magnetic discipline vector are at the same time perpendicular.

$F=J \times B$

Where $\mathrm{J}=$ Current per unit area $\mathrm{B}=$ Magnetic Field

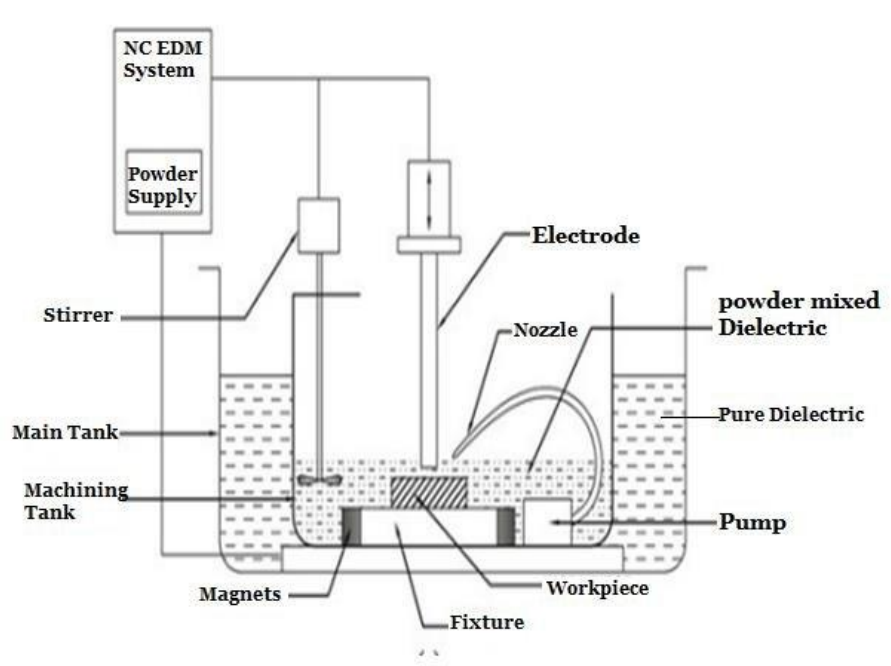

Figure 1: Experimental setup for EDM process [30] 


\section{EDM PARAMETERS}

\section{Non-electrical Parameters}

(1) Injection Flushing Pressure

(2) Rotational of speed electrode

Electrical Parameters
(1) Peak current
(2) Polarity
(3) Pulse duration
(4) Power supply voltage.

\subsection{Operating Parameters}

- On-time (Pulse time or T-on)

- Off-time (Pause time or T-off)

- $\quad$ Arc gap (gap)

- Duty cycle

- Intensity (I)

\section{CONCLUSION}

This evaluate is aimed toward optimizing the performance measures of EDM via thinking about the impact of various enter parameters on certain overall performance measures. Experimental research have been executed on exceptional cloth. Experiments had been carried out via various the peak current, pulse on time, pulse off time and voltage and the corresponding values of MRR, TWR, RWR and floor roughness are measure. The performance is suffering from discharge modern-day, pulse on time, pulse off time, arc hole, responsibility cycle, wire feed, cord tension, servo voltage, rotational speed, and flushing strain. The review paper evaluates the regions and subareas where optimization techniques were deployed. it really works on figuring out parameters for optimization and also suitable techniques for EDM mechanism.

\section{REFERENCES}

[1] U. Caydas, A. Hascalik, Modeling and analysis of electrode wear and white layer thickness in die-sinking EDM process through response surface methodology, International Journal of Advanced Manufacturing Technology, 38 (2008) 1148-1156.

[2] M.T. Yan, An adaptive control system with self-organizing fuzzy sliding mode control strategy for micro wire EDM machine, International Journal of Advanced Manufacturing Technology, 50 (2010) 315-328.

[3] O. Yilmaz, O. Eyercioglu, N.N.Z. Gindy, A user-friendly fuzzy based system for the selection of electro discharge machining process parameters, Journal of Materials Processing Technology, 172 (2006) 363-371.

[4] M. Zhou, F. Han, Adaptive control for EDM process with a selftuning regulator, International Journal of Machine Tools and Manufacture, 49 (2009) 462-469.

[5] M.T. Yan, H.T. Chien, Monitoring and control of the micro wireEDM process, International Journal of Machine Tools and Manufacture, 47 (2007) 148-157.

[6] Puri, A. B., Bhattacharya, B., 2005, Modeling and Analysis of White Layer Depth in a Wire-Cut EDM Process through Response Surface Methodology\|, International Journal of Advanced Manufacturing Technology, 301-307.

[7] El-Taweel, T. A., 2009, Multi-response Optimization of EDM with $\mathrm{Al}-\mathrm{Cu}-\mathrm{Si}-\mathrm{TiC} \mathrm{P} / \mathrm{M}$ Composite Electrodell, International Journal of Advanced Manufacturing Technology, 44:100-113.

[8] Lajis, Mohd Amri, Mohd Radzi, H.C.D., Nurul Amin, A.K.M.,2009, The Implementation of Taguchi Method on EDM Process of Tungsten Carbidell, European Journal of Scientific Research, 36(4):609-617.

[9] Tomadi, S.H., Hassan, M.A., Hamedon, Z, 2009, Analysis of the Influence of EDM Parameters on Surface Quality, Material Removal Rate and Electrode Wear of Tungsten Carbidell, International Multi Conference of Engineers and Computer Scientists,

[10] Asif Iqbal, A. K. M., Khan, Ahsan Ali, 2010, Modeling and Analysis of MRR, EWR and Surface Roughness in EDM Milling through Response Surface Methodologyll, American Journal of Engineering and Applied Sciences 3(4):611-619.

[11] Dewangan, Shailesh, Biswas, C. K., 2011, Experiment Investigation of Machining Parameters for EDM Using U- shaped Electrode of AISI P20 Tool Steell, an international conference on emerging trends in mechanical engineering, 1-6.

[12] Kumar Anish, Kumar Vinod, Kumar Jatinder, 2012, —Prediction of Surface Roughness in Wire Electric Discharge Machining (WEDM) Process based on Response Surface Methodologyll, International Journal of Engineering \& Technology, 2(4):708-719.

[13] T, Rajmohan, R., Prabhu, G., Subba Rao, K., Palanikumar, 2012, Optimization of Machining Parameters in Electrical Discharge Machining (EDM) of (304) stainless steell, International Conference on Modeling, Optimization, and Computing (ICMOC): 1030-1036.

[14] Subrahmanyam, S. V., Sarcar, M. M. M.,2013, Evaluation of Optimal Parameters for machining with Wire cut EDM Using GreyTaguchi Methodll, International Journal of Scientific and Research Publications, (2013),3(3):1-9

[15] Shah, C. D., Mevada, J. R., Khatri, B. C.,2013, Optimization of Process Parameter of Wire Electrical Discharge Machine by Response Surface Methodology on Inconel-600\|, International Journal of Emerging Technology and Advanced Engineering, 3(4):260-267.

[16] Sahoo, Manabhanjan, N. Pramanik, Rudra, Sahoo, Dipti R.2013, Experimental Investigation of Machining of Tungsten carbide by EDM and Its Mathematical Expressionll, International Journal of Mechanical and Production Engineering, 2(1):138-150.

[17] Laxman J, Guru Raj K, Rao Venkateshwara P, Dec 2015, EDM process parameters effects on Titanium super alloy, International Research Journal of Engineering and Technology, 02:508-513.

[18] Mohanty C. P., Mahapatra S. S., Singh M. R.,2017- An intelligent approach to optimize the EDM process parameters using utility concept and QPSO algorithm, Engineering Science and Technology an International Journal,20(2017):552-562.

[19] C. P. Mohanty, S. S. Mahapatra, and M. R. Singh, "An Experimental Investigation of Machinability of Inconel 718 in Electrical Discharge Machining," Procedia Mater. Sci., vol. 6, no. Icmpc, pp. 605-611, 2014, doi: 10.1016/j.mspro.2014.07.075.

[20] S. Kumar Sahu, T. Jadam, S. Datta, D. Dhupal, and G. Nandi, "Application of SiC Power Added in Kerosene Dielectric Media for Electro-Discharge Machining of Inconel 718 Super Alloys: Effect of 
Powder Concentration," Mater. Today, Proc., vol. 5, no. 9, pp. $20297-$ 20305, 2018, doi: 10.1016/j.matpr.2018.06.402.

[21] Rahul, S. Datta, and B. Bhusan Biswal, "Experimental studies on electro-discharge machining of Inconel 825 super alloy using cryogenically treated tool/workpiece," Meas. J. Int. Meas. Confed., vol. 145, pp. 611-630, 2019, doi: 10.1016/j.measurement.2019.06.006.

[22] J. Jeykrishnan, B. Vijaya Ramnath, N. Chenbhaga Ram, K. Nikhil, R. Naveen Babu, and D. Naveen, "Investigation on the Influence of Performance Characteristics on Machining Inconel 625 alloy in ElectroDischarge Machining (EDM)," Mater.Today Proc., vol. 5, no. 9, pp. 20449-20454, 2018, doi: 10.1016/j.matpr.2018.06.421.

[23] Rahul, S. Datta, B. B. Biswal, and S. S. Mahapatra, "Machinability analysis of Inconel 601, 625, 718 and 825 during electro-discharge machining: On evaluation of optimal

parameters setting," Meas. J. Int. Meas. Confed., vol. 137, pp. 382-400, 2019, doi: 10.1016/j.measurement.2019.01.065.

[24] B. K. Sahu, S. Datta, and S. S. Mahapatra, "On Electro-Discharge Machining of Inconel 718 Super Alloys: An Experimental Investigation," Mater. Today Proc., vol. 5, no. 2, pp. 4861-4869, 2018, doi: 10.1016/j.matpr.2017.12.062.

[25] Rahul, S. Datta, B. Bhusan Biswal, and S. Sankar Mahapatra, "Optimization of Electro-Discharge Machining Responses of Super Alloy Inconel 718: Use of Satisfaction Function Approach Combined with Taguchi Philosophy," Mater.Today Proc., vol. 5, no. 2, pp. 43764383, 2018, doi: 10.1016/j.matpr.2017.12.005.

[26] S. Raj et al., "Optimization of Surface Topography of ElectroDischarge Machined Super Alloy Inconel 825: Using TOPSIS Integrated with Taguchi Philosophy," Mater.Today Proc., vol. 24, pp. 218-224, 2020, doi: 10.1016/j.matpr.2020.04.270.

[27] A. Thakur, S. Dewangan, Y. Patnaik, and S. Gangopadhyay, "Prediction of Work Hardening during Machining Inconel 825 Using Fuzzy Logic Method," Procedia Mater. Sci., vol. 5, pp. 2046-2053, 2014, doi: 10.1016/j.mspro.2014.07.538.

[28] N. Singh, B. C. Routara, and D. Das, "Study of machining characteristics of Inconel 601 in EDM using RSM," Mater.Today Proc., vol. 5, no. 2, pp. 3438-3449, 2018, doi: 10.1016/j.matpr.2017.11.590. [29] A. Thakur, A. Mohanty, S. Gangopadhyay, and K. P. Maity, "Tool Wear and Chip Characteristics during Dry Turning of Inconel 825," Procedia Mater. Sci., vol. 5, pp. 2169-2177, 2014, doi: 10.1016/j.mspro.2014.07.422.

[30] https://www.researchgate.net/figure/Experimental-setupschematic-diagram-3-Results-and-Discussions-A-total-of-27-

xperiment_fig1_333631888 [20] Vijay Verma, Ram Sajeevan, Multi process parameter optimization of Die sinking EDM on Titanium alloy (Ti6Al4V) using Taguchi approach, Materials Today: Proceedings 2 (2015), 2581-2587. 